\title{
Olfactory Bulb Glomeruli: External Tufted Cells Intrinsically Burst at Theta Frequency and Are Entrained by Patterned Olfactory Input
}

\author{
Abdallah Hayar, Sergei Karnup, Michael T. Shipley, and Matthew Ennis \\ Department of Anatomy and Neurobiology, Program in Neuroscience, University of Maryland, Baltimore, Maryland 21201
}

\begin{abstract}
Glomeruli, the initial sites of synaptic processing in the olfactory system, contain at least three types of neurons collectively referred to as juxtaglomerular (JG) neurons. The role of JG neurons in odor processing is poorly understood. We investigated the morphology, spontaneous, and sensory-evoked activity of one class of JG neurons, external tufted (ET) cells, using whole-cell patch-clamp and extracellular recordings in rat olfactory bulb slices. ET cells have extensive dendrites that ramify within a single glomerulus or, rarely, in two adjacent glomeruli. All ET neurons exhibit spontaneous rhythmic bursts of action potentials $(\sim 1-8$ bursts $/ \mathrm{sec})$. Bursting is intrinsically generated; bursting persisted and became more regular in the presence of ionotropic glutamate and GABA receptor antagonists. Burst frequency is voltage dependent; frequency increased at membrane potentials depolarized relative to rest and decreased during membrane potential hyperpolarization. Spontaneous bursting persisted in blockers of calcium channels that eliminated low-threshold calcium spikes (LTS) in ET cells. ET cells have a persistent sodium current available at membrane potentials that generate spontaneous bursting. Internal perfusion with a fast sodium channel blocker eliminated spontaneous bursting but did not block the LTS. These results suggest that persistent sodium channels are essential for spontaneous burst generation in ET cells. ET cell bursts were entrained to ON stimuli delivered over the range of theta frequencies. Thus, ET cells appear to be tuned to the frequency of sniffing.
\end{abstract}

Key words: external tufted; bursting; coefficient of variation; persistent sodium current; entrainment; synchrony

\section{Introduction}

In mammals, olfactory nerve (ON) axons arising from olfactory receptor neurons expressing the same odorant receptor converge onto one or few glomeruli in each main olfactory bulb. Each glomerulus therefore represents the odorant specificity of the receptor expressed by the uniform population of olfactory receptor neurons that innervate it. Accordingly, each glomerulus is a functional unit for processing sensory input. Consistent with this, imaging studies have shown that individual odorants elicit specific spatial patterns of glomerular activity, and different odorants activate different patterns of glomeruli (Jourdan et al., 1980; Cinelli et al., 1995; Johnson and Leon, 2000a,b; Belluscio and Katz, 2001).

The glomeruli are the initial site of synaptic integration in the olfactory pathway. Within a glomerulus, ON axons synapse with the apical dendrites of mitral-tufted cells and with an extensive population of neurons intrinsic to the glomerular layer, the juxtaglomerular (JG) neurons. It is estimated that $\sim 25$ mitral cells

\footnotetext{
Received Oct. 18, 2003; revised Dec. 2, 2003; accepted Dec. 2, 2003.

This work was supported by National Institutes of Health Grants DC00347, DC02588, DC03195, and DC05676. We thank Dr. Kathryn Hamilton for her useful comments on this manuscript.

Correspondence should be addressed to Abdallah Hayar, Department of Anatomy and Neurobiology, University of Tennessee Health Science Center, 855 Monroe Avenue, Suite 515, Memphis, TN 38163. E-mail: ahayar@utmem.edu.

M. Ennis's present address: Department of Anatomy and Neurobiology, University of Tennessee Health Science Center, Memphis, TN 38163.

D01:10.1523/JNEUROSCI.4714-03.2004

Copyright $\odot 2004$ Society for Neuroscience $\quad$ 0270-6474/04/241190-10\$15.00/0
}

send a dendrite to each glomerulus; in contrast, there are as many as 1500-2000 JG neurons per glomerulus (Shipley et al., 1996). Despite their large number and strategic location, the functional roles of JG cells in olfactory processing are poorly understood.

Olfactory information is thought to be encoded, at least in part, by oscillating or bursting neural assemblies (Wehr and Laurent, 1996; Kauer, 1998; Kay and Laurent, 1999; Laurent, 2002). Previous intracellular recordings in vivo indicated that $\mathrm{ON}$ and odor stimulation produced bursts of action potentials in some JG cells (Getchell and Shepherd, 1975; Wellis and Scott, 1990). Moreover, in vitro whole-cell recordings indicate that some JG cells generate low-threshold spike bursts in response to depolarizing currents (McQuiston and Katz, 2001), but it has not been established whether any JG neuronal subtypes generate bursts spontaneously (i.e., without stimulation or current injection).

On the basis of preliminary experiments, external tufted (ET) cells appeared to spontaneously generate rhythmical bursts of action potentials (Hayar et al., 2001). Therefore, the goals of the present study were to characterize the physiological properties of morphologically confirmed ET cells in rat olfactory bulb slices, determine whether these cells intrinsically generate spontaneous bursting activity, and investigate the mechanism of spontaneous burst generation. Portions of this work have been published in abstract form (Hayar et al., 2001).

\section{Materials and Methods}

Sprague Dawley rats (21-29 d of age) of either gender were anesthetized with chloral hydrate and decapitated in accordance with Institutional 
Animal Care and Use Committee and National Institutes of Health guidelines. The olfactory bulbs were removed and immersed in sucrose-artificial CSF (sucrose-aCSF) equilibrated with $95 \% \mathrm{O}_{2}-5 \% \mathrm{CO}_{2}, \mathrm{pH} 7.38$. The sucrose-aCSF had the following composition (in mM): $26 \mathrm{NaHCO}_{3}, 1$ $\mathrm{NaH}_{2} \mathrm{PO}_{4}, 2 \mathrm{KCl}, 5 \mathrm{MgSO}_{4}, 0.5 \mathrm{CaCl}_{2}, 10$ glucose, and 248 sucrose. Horizontal slices (400 $\mu \mathrm{m}$ thick) were cut with a microslicer (Ted Pella, Redding, CA). After a period of recovery at $30^{\circ} \mathrm{C}$ for $15 \mathrm{~min}$, slices were then incubated at room temperature $\left(22^{\circ} \mathrm{C}\right)$ in aCSF equilibrated with $95 \% \mathrm{O}_{2}-5 \% \mathrm{CO}_{2}$ [composition (in mM): $124 \mathrm{NaCl}, 26 \mathrm{NaHCO}_{3}, 3 \mathrm{KCl}, 1.25 \mathrm{NaH}_{2} \mathrm{PO} 4,2$ $\mathrm{MgSO}_{4}, 2 \mathrm{CaCl}_{2}$, and 10 glucose] until they were used. For recording, a single slice was placed in a recording chamber and continuously perfused at the rate of $1.5 \mathrm{ml} / \mathrm{min}$ with normal aCSF equilibrated with $95 \% \mathrm{O}_{2}-5 \% \mathrm{CO}_{2}$. All recordings were performed at $30^{\circ} \mathrm{C}$ unless otherwise mentioned. Neurons were visualized using an upright microscope (BX50WI; Olympus Optical, Tokyo, Japan) equipped for epifluorescence and near-infrared differential interference contrast optics.

Patch pipettes were pulled from borosilicate glass capillaries with an inner filament (1.5 mm outer diameter; Clark Electromedical Instruments, Kent, UK) on a pipette puller (P-97; Sutter Instruments, Novato, $\mathrm{CA}$ ) and were filled with a solution of the following composition (in mM): $114 \mathrm{~K}$-gluconate, $17.5 \mathrm{KCl}, 4 \mathrm{NaCl}, 4 \mathrm{MgCl}_{2}, 10 \mathrm{HEPES}, 0.2$ EGTA, 3 $\mathrm{Mg}_{2}$ ATP, $0.3 \mathrm{Na}_{2} \mathrm{GTP}, 0.02 \%$ Lucifer yellow, and $0.2 \%$ biocytin (Molecular Probes, Eugene, OR). Osmolarity was adjusted to $270 \mathrm{mOsm}, \mathrm{pH}$ 7.3. Extracellular recordings were obtained using patch pipettes filled with aCSF. The pipette resistance was 5-8 M 2 . Whole-cell voltageclamp recordings were made with the Axopatch-200B amplifier (Axon Instruments, Foster City, CA). The liquid junction potential was 9-10 $\mathrm{mV}$, and all reported voltage measurements were not corrected for these potentials. Only neurons that had access resistance of $<30 \mathrm{M} \Omega$ were included in this study. No series resistance compensation was performed. The input resistance of recorded neurons was measured between -60 and $-70 \mathrm{mV}$. Electrical stimulation (Grass $\$ 8800$ stimulator; Astro-Med, West Warwick, RI) was performed using two stainless steel wires (50 $\mu \mathrm{m}$ in diameter; A-M Systems, Everett, WA), insulated except at their tips positioned in the ON layer. Isolated, constant-current stimulus pulses of $10-200 \mu \mathrm{A}$ and $100 \mu \mathrm{sec}$ duration were applied.

Drugs and solutions of different ionic content were applied to the slice by switching the perfusion with a three-way electronic valve system. Tetrodotoxin (TTX), N-ethyl bromide quaternary salt (QX-314), gabazine (SR95531), 6-cyano-7-nitroquinoxaline-2,3-dione (CNQX), and (士)-2-amino-5-phosphopentanoic acid (APV) were purchased from Research Biochemicals (Natick, MA). 2-Methyl-6-(phenylethynyl)pyridine hydrochloride (MPEP), 7-(hydroxyimino)cyclopropa[b]chromen-1acarboxylate ethyl ester (CPCCOEt), and (2S)-2-amino-2-[(1S,2S)-2carboxycycloprop-1-yl]-3-(xanth-9-yl) propanoic acid (LY 341495) were purchased from Tocris Cookson (Ellisville, $\mathrm{MO}$ ).

After electrode withdrawal from cells, the images of the recorded neurons (labeled with Lucifer yellow) were digitized using a video card (Scion, Frederick, MD) and saved for later comparison with biocytin-labeled cells after histological processing. The biocytin-filled cells were developed as described previously (Karnup and Stelzer, 1999). Briefly, fixed slices were embedded in $10 \%$ gelatin and sectioned at $80 \mu \mathrm{m}$ thickness using a vibratome. The sections were reacted with $1 \% \mathrm{H}_{2} \mathrm{O}_{2}, 0.5 \%$ Triton X-100, $\mathrm{ABC}$ complex, and $\mathrm{Ni}-\mathrm{DAB}$ chromagen. After dehydration, the sections were mounted in DPX (a mixture of distyrene, tricresyl phosphate, and xylene). Two-dimensional reconstructions of filled neurons were made with Neurolucida software (MicroBrightField, Colchester, VT).

Analog signals were low-pass filtered on-line at $2 \mathrm{kHz}$ (Axopatch 200B), digitized at $10 \mathrm{kHz}$ (InstruTech, Long Island, NY), and stored on videotape for later analysis. They were also digitized at $5-10 \mathrm{kHz}$ using a Digidata-1200A interface and pClamp8 software (Axon Instruments). The detection of extracellularly recorded action potentials-currents was performed off-line using Mini analysis program (Synaptosoft, Decatur, GA). The times of occurrence of spikes were stored in American Standard Code for Information Interchange files and imported into Origin 7.0 (Microcal Software, Northampton, MA) for additional analysis using algorithms written in LabTalk language. The coefficient of the variation $(\mathrm{CV})$ of the interburst time intervals and the spike train crosscorrelograms (bin, 1 or $2 \mathrm{msec}$ ) was obtained using data acquired during
5-10 min in each recording condition. The cross-correlograms were normalized by dividing the counts in each bin by a coefficient $(N)$, which is the number of events expected by chance during one bin:

$$
N=F \times F \times P \times B,
$$

where $F$ is the mean frequency of spikes (Hertz), $P$ is the sampling period (in seconds) used for analysis, and $B$ is the duration of one bin (in seconds).

Data expressed as mean \pm SEM were statistically analyzed using Origin 7.0 software with paired $t$ tests unless otherwise stated.

\section{Results}

Whole-cell patch-clamp and extracellular recordings were obtained from anatomically identified JG neurons. Patch-clamped cells were filled with Lucifer yellow for on-line visualization and biocytin for post hoc morphological reconstruction and analysis. JG cells were classified as ET, short axon (SA), or periglomerular (PG) cells. In the course of these experiments, it became clear that ET cells were readily distinguishable from other JG cell types not only by their distinctive morphology but also by their unique physiological properties. The properties of ET cells were investigated in further detail.

\section{Morphology of external tufted cells}

Tufted cells of the main olfactory bulb have been classified into three categories according to localization of their cell bodies: deep, middle, and external (Pinching and Powell, 1971a; Macrides and Schneider, 1982). Tufted cells with somata localized within the glomerular layer (GL) or at the GL-external plexiform layer (EPL) border are defined as ET cells (Figs. 1, 2A). Morphological data were obtained from 65 anatomically identified ET cells. ET cell bodies are located predominantly in the deeper half of the glomeruli. The vast majority ( 61 of $65 ; \sim 94 \%$ ) have a single thick apical dendrite ramifying as a distinctive tuft within a single glomerulus. Only 4 of 65 ( $\sim 6 \%)$ ET cells were "bitufted" with two tufts, ramifying in adjacent glomeruli.

Morphological parameters were quantified for 27 of 65 randomly selected ET cells. ET cells have a relatively large (area, $87.9 \pm 7.8 \mu \mathrm{m}^{2}$ ) pear-shaped cell body. The length of the primary shaft (defined as the distance from the soma to the first branch within a glomerulus) varied from 1 to $68 \mu \mathrm{m}(27.4 \pm 3.3$ $\mu \mathrm{m})$. In agreement with a recent study (McQuiston and Katz, 2001), most ET cells (71\%) lacked visible spines; in the remaining $29 \%$, dendritic spines were present but sparsely (15.2 \pm 3 spines/ cell; range, 4-38) (Fig. 1G). ET cells have the most extensive intraglomerular dendritic ramification of all JG cell types. The ET cell apical tuft occupied on average $79.1 \pm 5.1 \%$ (range, 20$100 \%$ ) of the area of a glomerulus in two-dimensional reconstruction (Fig. 1). This is $\sim 300 \%$ greater than the average area of the PG cells sampled $(24.9 \pm 0.1 \% ; n=32)$ and $27 \%$ greater than the mean dendritic area of mitral cells $(61.7 \pm 7.5 \% ; n=11)$ (our unpublished observations).

Secondary dendrites were present in 37\% (10 of 27) of ET cells. These dendrites extended to the EPL in one-half ( 5 of 10) of this subset of ET cells; for the remainder, the dendrites were truncated within the GL at a short distance from the soma (1-20 $\mu \mathrm{m} ; 4$ of 10 cells) or the dendrite ramified within the GL ( 1 of 10 cells). Axons were visible in 63\% (17 of 27) of the filled ET cells analyzed. In $71 \%$ (12 of 17) of these cells, the axon coursed into the superficial EPL, and in $16 \%$ ( 2 of 12 cells) coursed into the granule cell layer. In the remaining cells ( 5 of 17), the axon was truncated within the GL but coursed toward the EPL. Because long processes were often truncated in the slice, ET cell secondary dendrites and axons were not analyzed quantitatively. 


\section{External tufted cells burst rhythmically} ET cells were initially recorded in wholecell current clamp-configuration and filled with biocytin, so that their electrophysiological properties could be correlated with their morphology. ET cells had a resting membrane potential of $-52.9 \pm 1.0 \mathrm{mV}$ and an input resistance of $194 \pm 32 \mathrm{M} \Omega$ $(n=12)$. The most conspicuous physiological characteristic of all morphologically confirmed ET cells is that they spontaneously generate rhythmical bursts of action potentials superimposed during a slow depolarizing envelope (Fig. $2 \mathrm{~A}$ ). The spontaneous burst frequency of ET cells measured within the first 2 min of wholecell recording (see below) ranged from 0.5 to 6.5 bursts/sec with a mean frequency of $2.7 \pm 0.4$ bursts/sec $(n=26)$. Bursts consisted of two or more action potentials riding on a distinct slow $(101 \pm 7.6 \mathrm{msec}$ in duration; $n=26$ ) depolarizing envelope averaging $6.3 \pm 0.4 \mathrm{mV}$ in amplitude. The average membrane potential from which spikes were launched was $-46.5 \pm 0.8 \mathrm{mV}$ $(n=22)$.

No other JG neuron types exhibited this spontaneous bursting behavior. The morphological and physiological characteristics of PG $(n=30)$ and SA cells $(n=$ 11 ) were distinct from ET cells (Fig. $2 B$ ). PG cells have a relatively small soma (mean, $47 \pm 10 \mu \mathrm{m}^{2}$ ). They have either one to three relatively thick primary dendritic shafts that give rise to thinner branches ramifying within a single glomerulus or several very thin dendrites that ramify close to the soma. Spines were present on $60 \%$ of PG cells. PG cells had resting membrane potentials ranging from -69 to $-62 \mathrm{mV}(-65 \pm$ $2 \mathrm{mV} ; n=48)$. The input resistance of PG cells $(567 \pm 91 \mathrm{M} \Omega$; $n=12)$ was significantly higher than that of ET neurons $(p<$ 0.01 ; unpaired $t$ test). PG cells also had very different spontaneous (Fig. 2B) and current-induced activity from ET cells. They seldom generated spontaneous action potentials at rest. Positive current injection induced single action potentials; further depolarization caused regular firing and eventually spike inactivation (Fig. 2 B). Current injections did not evoke slow depolarizations similar to those in ET cells, suggesting that PG cells lack the intrinsic capacity to generate rhythmic bursting. However, PG cells were characterized by spontaneous rhythmic bursts of EPSPs-EPSCs that could trigger one or a few spikes (Fig. $2 B$ ). SA cells $(n=11)$ had relatively thin axons $(<0.5 \mu \mathrm{m}$ diameter) that ramified up to $850 \mu \mathrm{m}$ exclusively within the GL. SA cell bodies averaged $89.7 \pm 16.0 \mu \mathrm{m}^{2}$, and they had three to five $(3.2 \pm 0.3)$ poorly branched dendrites that contacted two to four glomeruli. Their resting membrane potentials were $-62.3 \pm 1.3 \mathrm{mV}$, and they had mean input resistance of $642 \pm$ $114 \mathrm{M} \Omega$. Like PG cells, SA cells neither exhibited spontaneous bursts of action potentials nor generated bursts of action potentials in response to depolarizing current injections. However, they did exhibit spontaneous bursts of EPSPs that occasionally gave rise to one or two action potentials.

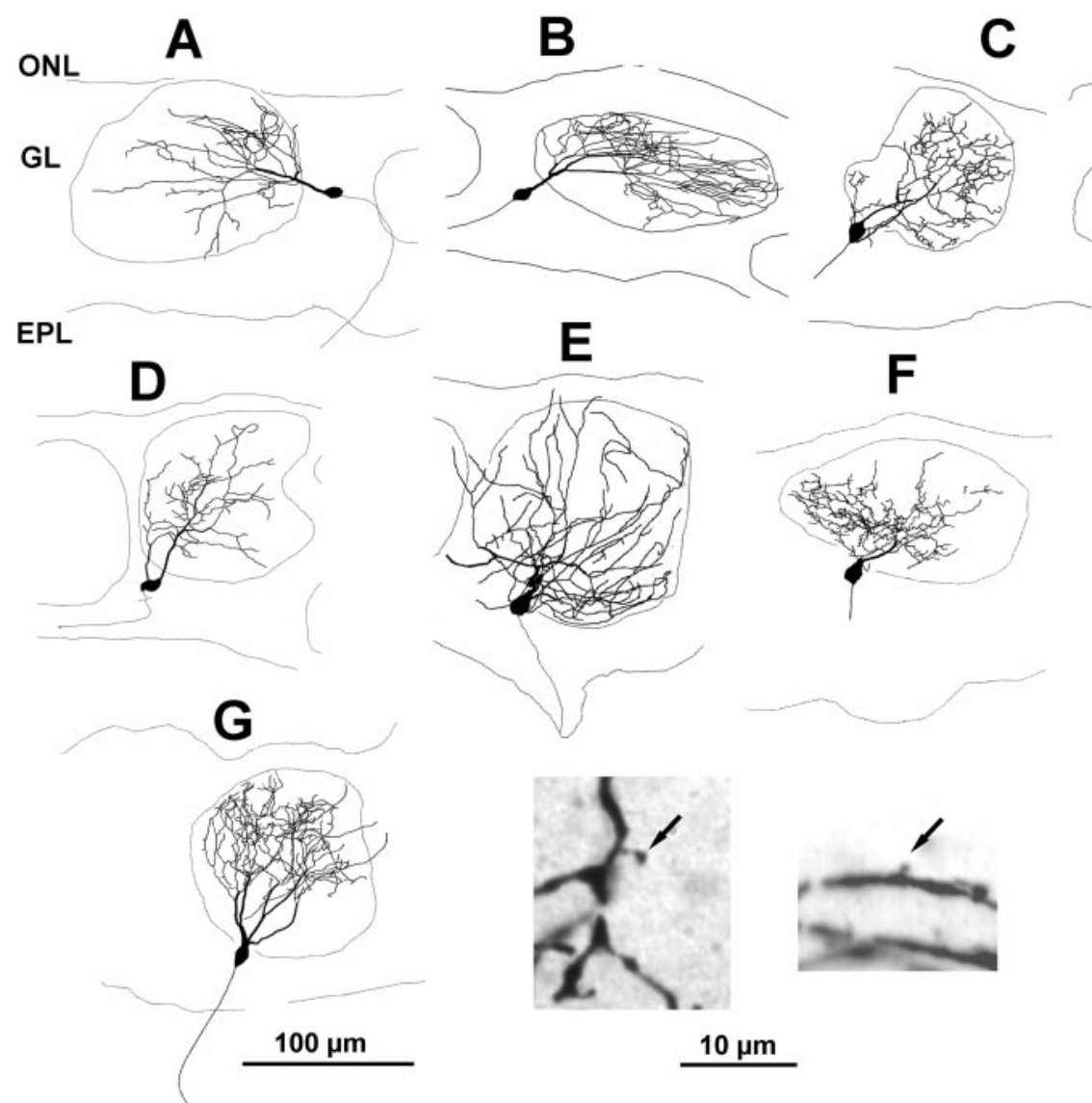

Figure 1. Morphology of ET cells. A-G, Neurolucida drawings of typical ET cells. The highly branched tufted dendrites ramify this and subsequent figures indicate boundaries of the GL with the olfactory nerve layer (ONL) and EPL, respectively. Scale bar (in $G): A-G, 100 \mu \mathrm{m}$. The two photographs in $G$ show typical spines (arrows) on the dendrites of the same ET cell.

\section{Frequency and regularity of bursting}

Because mechanical perturbation or intracellular dialysis associated with whole-cell recordings could potentially influence the spontaneous activity of ET cells, we compared the activity of six ET cells recorded initially in cell-attached mode (Fig. $3 A$ ) with that immediately following establishment of whole-cell recording. The mean bursting frequency was stable over a $\sim 5$ min epoch in the cell-attached recording mode (first min, $2.2 \pm 0.5$ bursts/sec; last min, $2.0 \pm 0.4$ bursts/sec). The bursting frequency of the same cells was not significantly different when measured immediately (within $30 \mathrm{sec}$ ) after going into the whole-cell configuration ( $2.1 \pm 0.5$ bursts/sec; $p=0.95$; one-way ANOVA). However, during maintained whole-cell recordings, ET cell bursting frequency slowly decreased and, in all cells, bursting ceased after $2-15$ min (mean, $7.2 \pm 1.9 \mathrm{~min}$ ) (Fig. $3 A$ ). A single exponential analysis of the decay in bursting frequency monitored over $18 \mathrm{~min}$ of whole-cell recording yielded a time constant $(\tau)$ of $2.2 \mathrm{~min}(n=6)$; this value is associated with a $63.2 \%$ reduction in burst frequency (Fig. $3 A$ ). By 30 min of whole-cell recording, bursting was abolished, and large intracellular current injections (300-500 pA) elicited single spikes but not bursting. Over this same period, the resting potential of ET cells (mean initial value, $-57.8 \pm 0.7 \mathrm{mV}$ ) progressively hyperpolarized by an average $14 \mathrm{mV}$ to a steady-state level of $-72.0 \pm 1.9 \mathrm{mV}$, and the input resistance decreased by $56 \pm 5 \%$ (from $221 \pm 45$ to $92 \pm 15 \mathrm{M} \Omega ; n=4 ; p<0.05)$. These findings indicate that rhythmic bursting is the intrinsic spontaneous activity state of ET 

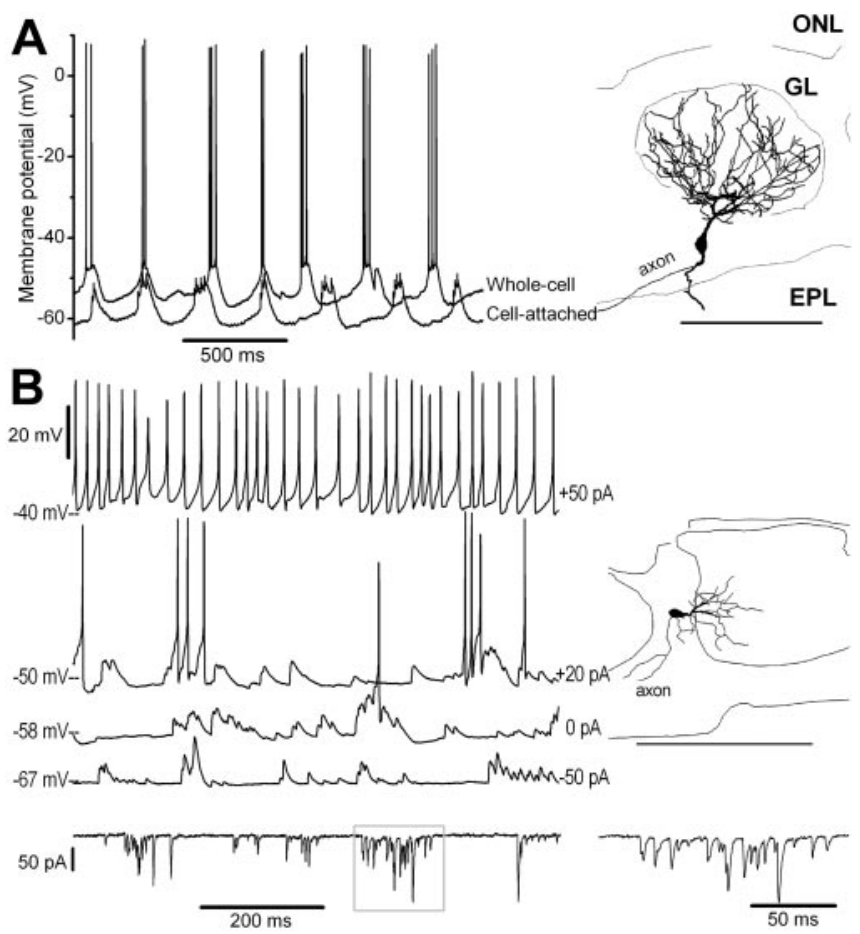

Figure 2. ET cells burst rhythmically, whereas PG cells exhibit burst of EPSPs. A, The left panel shows recordings from the same ET cell in cell-attached mode (bottom trace; spikes truncated because of membrane filtering during gigaohm seal recording) and whole-cell configuration (top trace; 1 min after rupturing the membrane). The frequency $(\sim 3 \mathrm{~Hz}$ ) and pattern of bursting were comparable in cell-attached and whole-cell modes. The right panel shows the morphology of the same ET cell. Note the highly branched dendritic tuft that ramifies throughout a single glomerulus. Scale bar, $100 \mu \mathrm{m}$. ONL, Olfactory nerve layer. B, Top traces, Current-clamp recordings show effects of steady hyperpolarizing or depolarizing current injection in a typical PG cell. At rest $(0 \mathrm{pA})$, the cell receives spontaneous bursts of EPSCs and generates spikes infrequently, notably during bursts of EPSPs. The cell did not generate spike bursts after depolarizing or hyperpolarizing current injection. Reconstruction of the recorded cell at the left shows typical morphology of $\mathrm{PG}$ cell, including relatively small soma and one to three relatively thick primary dendritic shafts, which give rise to thinner branches ramifying within a subregion of a single glomerulus. Scale bar, $100 \mu \mathrm{m}$. Bottom traces, Voltage-clamp recording (holding potential, $-60 \mathrm{mV}$ ) shows bursts of spontaneous EPSCs in the same PG cell; region enclosed in the box is shown at faster time scale at right.

cells, and that the frequency of bursting progressively declines after establishment of whole-cell recordings, probably as a result of intracellular dialysis.

Because of this "rundown" effect, the burst frequency of ET cells could have been underestimated in whole-cell recordings. To obviate this problem, we took advantage of the fact that only ET cells exhibited spontaneous bursting behavior and used extracellular or cell-attached recordings to analyze burst frequency in a large population of ET cells. For 110 cells, the frequency of bursting ranged from 0.4 to 8.8 bursts/sec with a mean of $3.3 \pm$ 0.18 bursts/sec (Fig. $3 B$ ) compared with a mean burst frequency of $2.7 \pm 0.4 \mathrm{bursts} / \mathrm{sec}$ in a population of $26 \mathrm{ET}$ cells recorded in whole-cell mode (see above). The median burst frequency was 3.0 (i.e., half of the ET cells have a spontaneous burst frequency slower, and half faster, than 3 bursts/sec) (Fig. $3 B$ ). The average number of spikes/burst was $5.4 \pm 0.3$ (range, $2-12 ; n=72$ cells). The average interspike interval within a burst was $8.4 \pm 0.5 \mathrm{msec}$ (range, 3.4-18 msec; $n=68$ cells), corresponding to an intraburst discharge rate of $\sim 117 \mathrm{~Hz}$. The average duration of a spike burst (mean interval between the first and last spike in a burst) was $32 \pm 2.4 \mathrm{msec}(n=71$ cells; range, $5-73 \mathrm{msec})$. Thus, the
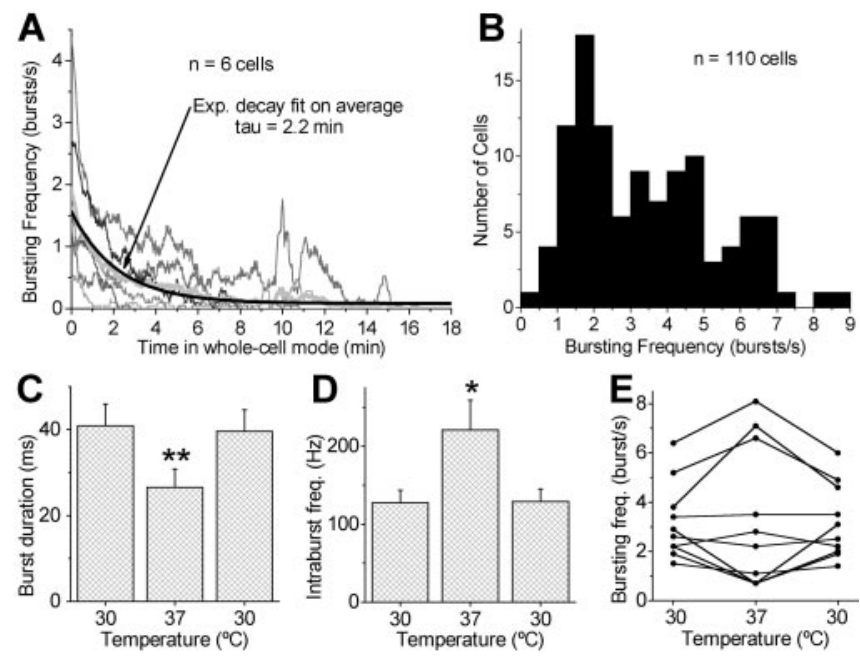

Figure 3. Effect of rundown and temperature on bursting frequency. $A$, The bursting exhibits rundown in whole-cell mode. Line graphs show bursting frequency from six cells (thin lines; bin, $1 \mathrm{sec}$; smooth averaging $20 \mathrm{sec}$ ) in whole-cell mode. Time 0 is when recording configuration was switched from cell-attached to whole-cell mode. The average histogram (gray thick line) of the six traces was fitted with an exponential decay function (black line curve). Note that ET cells with an initial high bursting frequency took longer to stop bursting. The time constant $(\tau)$ of the decay of bursting frequency was $2.2 \mathrm{~min}$, which was the time at which the average bursting had decreased by $63.2 \%$ relative to the initial frequency. $B$, Frequency distribution of the mean bursting rate in $E T$ cells recorded extracellularly or in cell-attached mode. $C-E$, The effects of increasing the temperature from 30 to $37^{\circ} \mathrm{C}$ were tested on $10 \mathrm{ET}$ cells recorded extracellularly. Increasing the temperature consistently decreased the burst duration and consistently increased the intraburst frequency as shown in the grouped data. In contrast, raising the temperature did not produce a consistent effect on the bursting frequency. All effects were reversible. ${ }^{*} p<0.01$; ${ }^{* *} p<0.0001$.

average duration of a spike burst was less than the duration of the underlying membrane depolarization (101 msec; see above).

As shown below, bursting is attributable to intrinsic membrane properties of ET cells. Therefore, it is possible that the frequency of ET cell bursting is temperature dependent. To investigate this, we varied the temperature in the recording chamber (Fig. 3). After increasing the temperature from 30 to $37^{\circ} \mathrm{C}$, the burst duration decreased in all cells tested by an average of $37 \pm$ $3 \%$ (from $41 \pm 5$ to $27 \pm 4 \mathrm{msec} ; n=10 ; p<0.0001$ ) (Fig. $3 C$ ). The intraburst frequency increased in all cells by an average of $68 \pm 15 \%$ (from $127 \pm 16$ to $221 \pm 38 \mathrm{~Hz} ; n=10 ; p<0.01$ ) (Fig. $3 D)$, suggesting that the decrease in burst duration was not because of decreased numbers of spikes per burst. However, increasing the temperature did not consistently influence interburst frequency. Burst frequency increased in 5 of 10 cells and decreased in the remaining 5 cells (Fig. $3 E$ ). All changes in burst characteristics associated with increased temperature were reversible after cooling back to $30^{\circ} \mathrm{C}$. These results indicate that increasing the temperature to near physiological level in our in vitro conditions may slightly broaden the range of mean bursting frequencies of ET cells. However, the results suggest that in vitro recordings at $30^{\circ} \mathrm{C}$ do not systematically underestimate ET cell burst frequencies when measured near the physiological temperature of $37^{\circ} \mathrm{C}$.

Although the mean spontaneous bursting frequency varied among ET cells, the mean bursting frequency for each cell was relatively constant. To quantify the regularity of bursting, we calculated the CV (SD divided by the mean) of the interburst intervals. The lower the $\mathrm{CV}$, the more consistent the interburst intervals and the more regular the bursting; the higher the $\mathrm{CV}$, 

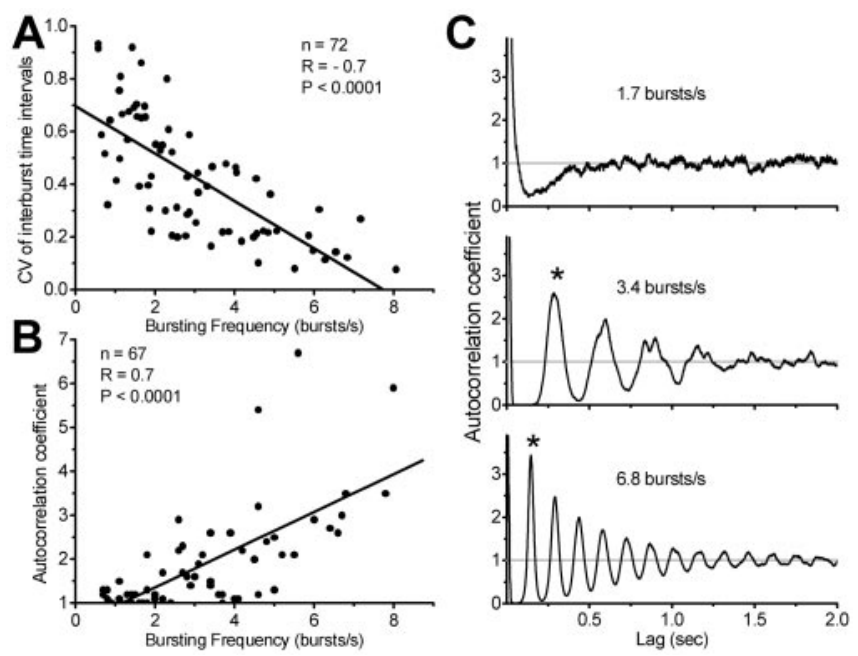

Figure 4. Rhythmic bursting is more regular in ET cells with higher spontaneous burst frequencies. A, Scatter plot showing the CV of the interburst time intervals as a function of the spontaneous bursting frequency ( $n=72$ cells). The reduction in CV with high bursting frequency, as shown by the linear regression fit (line), is indicative of an increase in regularity of bursting. $B$, Scatter plot showing the autocorrelation coefficient (measured as the amplitude of the first peak in the autocorrelograms), indicated by asterisks in (as a function of spontaneous bursting frequency ( $n=67$ cells). The linear regression fit (line) indicated that bursting is more regular in cells that have relatively high bursting frequency. C, Autocorrelograms of the spike trains of three ET cells with different mean bursting frequencies. The most regular burst oscillations occurred in the cell with the highest bursting frequency (bottom autocorrelogram). Data in this figure were obtained from recordings made in control conditions.

the more variable the bursting (Christodoulou and Bugmann, 2001). The average $C V$ of the interburst intervals was $0.43 \pm 0.03$ $(n=72$ cells; range, $0.08-0.93)$. The wide range in CV $(0.08-$ 0.93 ) and the wide range of bursting frequencies (0.5-8.5 bursts/ $\mathrm{sec}$ ) across the population of ET cells sampled prompted us to ask whether bursting regularity was related to the mean frequency of bursting in individual cells? We therefore examined autocorrelations of spike bursts in 67 ET cells. Unlike the CV, which only considers intervals between consecutive bursts, autocorrelation analysis takes into account all spike time intervals up to the duration of the window of analysis. Autocorrelation analysis can thus detect the presence of regular oscillatory activity (Perkel et al., 1967). This analysis showed that the rhythmic oscillatory bursting is most prominent in ET cells with higher spontaneous burst frequencies (Fig. 4B,C). The autocorrelation coefficient (measured as the amplitude of the first peak in the autocorrelograms) was positively correlated with the bursting frequency $(n=$ $67 ; r=0.7 ; p<0.001$ ) (Fig. $4 B$ ), whereas the CV was negatively correlated with the bursting frequency $(n=72 ; r=-0.7 ; p<$ 0.001 ) (Fig. 4A). Burst regularity is therefore proportional to burst frequency. As burst frequency increases, interburst interval may approach a limit set by intrinsic membrane properties and be less influenced by extrinsic sources of variability in the form of synaptic inputs. Therefore, we next tested for the influence of membrane voltage and synaptic input on ET spontaneous activity.

\section{Bursting is an intrinsic property of ET cells}

The rhythmical bursting behavior of ET cells could be attributable to intrinsic membrane properties, periodic synaptic input, or a combination of both. The finding that each ET cell has its own characteristic burst frequency suggests that burst rate is not determined primarily by rhythmic synaptic input, as this would

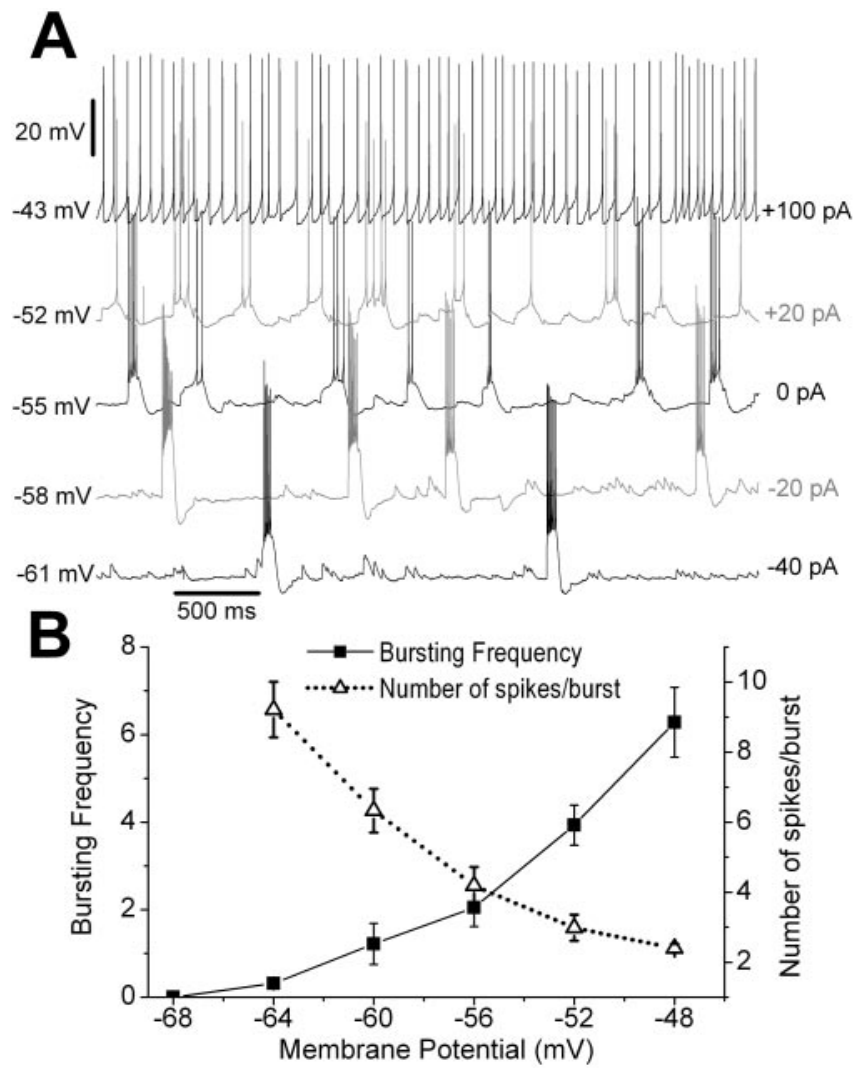

Figure 5. Bursting frequency and the number of spikes per burst are voltage dependent. $A$, Current-clamp recordings show effects of steady current injection on bursting activity in an ET cell. Spontaneous activity at rest $(0 \mathrm{pA})$ is characterized by spike bursts riding on slow depolarizing envelope. Hyperpolarizing current $(-20$ or $-40 \mathrm{pA})$ reduced the burst frequency and increased the number of spikes per burst, whereas depolarizing current $(+20 \mathrm{pA})$ increased bursting frequency and decreased the number of spikes per burst. Irregular firing was produced with more positive current injection $(+100 \mathrm{pA})$. $B$, Grouped data from six cells showing the inverse relationship between the bursting frequency and the number of spikes per burst when the membrane potential was hyperpolarized from -48 to $-64 \mathrm{mV}$.

imply that each ET cell receives input predominantly from synapses that are rhythmically "active" within a narrow frequency range. Furthermore, the finding that bursting progressively slowed and was finally eliminated by rundown suggests that the burst rate of each ET cell is primarily determined by intrinsic properties, such as voltage-gated conductances. To investigate this, we assessed the voltage dependence of bursting in currentclamp mode (Fig. 5). In this and all subsequent whole-cell recordings, data were collected within the first 2 min after membrane rupture to minimize the impact of rundown.

As shown in Figure 5, hyperpolarizing ET cells by negative current injection (range, -10 to $-100 \mathrm{pA}$ ) decreased burst frequency and increased both the amplitude of the rhythmic membrane depolarizations and the number of spikes per burst $(n=15$ of 15 cells) (Fig. $5 A$ ). Depolarizing the cells by positive current (20-50 pA) had the opposite effects: it increased burst frequency and decreased both the amplitude of the membrane depolarizations and the number of spikes per burst. Further depolarization (100 pA) changed the firing pattern from a bursting to either a regular or an irregular nonrhythmic firing pattern. The relationship between bursting pattern and membrane potential was analyzed in six ET cells (Fig. 5B). Hyperpolarization of the membrane potential from -52 to $-60 \mathrm{mV}$ decreased the bursting frequency from $3.9 \pm 0.5$ to $1.2 \pm 0.4$ bursts $/ \mathrm{sec}(p<0.01)$, 


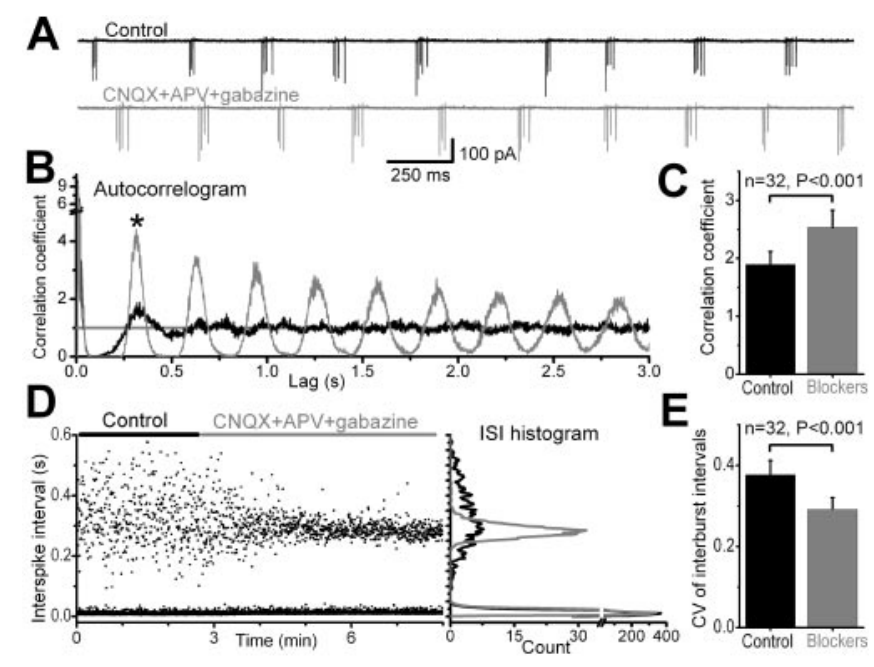

Figure 6. Bursting persists and becomes more regular in the presence of blockers of ionotropic receptor-mediated synaptic transmission. $A$, The two traces show extracellular recordings (in voltage-clamp mode) from a rhythmically bursting ET cell; downward deflections represent bursts of action currents in control (black trace) and during application of the synaptic blockers, $\mathrm{CNQX}+\mathrm{APV}+$ gabazine (gray trace). Note that the interburst intervals became less variable in the presence of the blockers. $B$, Autocorrelograms of the spike train from the cell recorded in $A$, before (black trace) and during (gray trace) application of the blockers. The blockers lead to the emergence of multiple peaks at $\sim 300$ msec intervals, indicative of an increase in the regularity of bursting. $C$, Grouped data from 32 cells showing a significant increase in the amplitude of the first peak in the autocorrelogram ( $B$, asterisk). $D$, A scatter plot (left panel) and a histogram (bin, 2 msec; right panel) of the interspike time intervals (ISIs) from the cell recorded in $A$. Note that the interburst time intervals (ISI, $>75 \mathrm{msec}$ ) became less variable in the presence of the blockers. E, Grouped data from 32 cells showing that the CV was significantly reduced during application of the synaptic blockers.

whereas the amplitude of the depolarizing envelope increased from $8.2 \pm 1.0$ to $19.5 \pm 1.7 \mathrm{mV}(p<0.01)$, and the number of spikes per burst increased from $3.0 \pm 0.4$ to $6.3 \pm 0.6(p<0$ 0.01 ). These results show that burst frequency is proportional to membrane potential (i.e., burst rate is voltage dependent). In addition, there is an inverse relationship between the burst frequency and the number of spikes per burst. As a consequence, the average firing frequency (number of spikes per second) did not change significantly as the membrane potential was varied from -52 to $-60 \mathrm{mV}(6.9 \pm 0.6$ vs $7.5 \pm 0.5$ spikes $/ \mathrm{sec} ; p=0.4)$. Thus, the membrane potential determines the firing pattern (bursting frequency and number of spikes per burst) of ET cells without significantly changing the mean firing frequency.

The voltage dependence of burst frequency suggests that rhythmic bursting is attributable to intrinsic membrane properties of ET cells rather than periodic synaptic input. To further examine this, we asked whether or not blockade of synaptic transmission altered bursting behavior (Fig. 6). In 57 neurons, recorded either extracellularly $(n=53)$ or in whole-cell configuration $(n=4)$, we collected baseline data on spontaneous bursting and then blocked GABA $\mathrm{A}_{\mathrm{A}}$ NMDA, and AMPA-kainate receptors by applying gabazine $(10 \mu \mathrm{M})$, APV $(50 \mu \mathrm{M})$, and CNQX $(10 \mu \mathrm{M})$. Rhythmic bursting persisted in $91 \%$ of the cells. In all four cells recorded in whole-cell mode, both the rhythmic membrane depolarizations and the associated spike bursts persisted in the presence of synaptic blockers (data not shown). Furthermore, the mean burst frequency was unchanged by the synaptic blockers in 48 of the 53 cells recorded extracellularly (range, 0.5-6.5 bursts/ sec; control, $2.9 \pm 0.2$ bursts/sec; blockers, $2.9 \pm 0.2$ bursts $/ \mathrm{sec}$; $n=48 ; p=0.73$ ) (Fig. $6 A)$. In 5 of 53 cells $(1.2 \pm 0.3$ bursts $/ \mathrm{sec}$; range, $0.6-2.2$ bursts/sec), the bursting stopped after application of the synaptic blockers. There is evidence that ET cells express metabotropic glutamate receptors (mGluRs) (Ohishi et al., 1995; Kinzie et al., 1997; Sahara et al., 2001). To determine whether mGluRs play a role in bursting, we investigated the effects of mGluR receptor blockers in four ET cells recorded extracellularly and two recorded in whole-cell mode. The group I and II mGluR antagonists (MPEP, $5 \mu \mathrm{M}$; CPCCOEt, $50 \mu \mathrm{M}$; LY 341495, $1 \mu \mathrm{M}$ ) were added in the presence of CNQX, APV, and gabazine. In all cases, bursting was unaffected by $\mathrm{mGluR}$ receptor blockers (control, $1.6 \pm 0.2$ bursts $/ \mathrm{sec}$; antagonists, $1.6 \pm 0.2$ bursts $/ \mathrm{sec} ; p=$ $0.7)$.

The lack of effect of the receptor blockers indicates that the generation of rhythmic bursting in ET cells does not depend on synaptic input. However, synaptic activity does modulate spontaneous bursting without changing the mean burst frequency (Fig. 6A). The application of synaptic blockers produced a more regular burst oscillation pattern as seen in the autocorrelograms of the spike trains (Fig. 6B). The coefficient of autocorrelation increased significantly in the presence of synaptic blockers, from $1.9 \pm 0.2$ in control aCSF to $2.5 \pm 0.3(n=32 ; p<0.001)$ (Fig. $6 B, C)$. Moreover, the $\mathrm{CV}$ of the interburst intervals was reduced from $0.38 \pm 0.04$ in control aCSF to $0.29 \pm 0.03(n=32 ; p<$ 0.001 ) (Fig. $6 D, E$ ). Thus, reduction or elimination of fast synaptic input significantly increased the regularity of bursting, suggesting that spontaneous synaptic input causes ET cells to deviate from their regular intrinsic bursting frequency.

\section{Currents underlying spontaneous bursting activity}

A recent study by McQuiston and Katz (2001) divided JG cells into two classes on the basis of their responses to intracellular current injections. One class, including ET cells, responded to depolarizing injections with a low-threshold calcium-dependent spike (LTS), which frequently generated a burst of action potentials; the LTS was blocked by $1 \mathrm{~mm}$ nickel $\left(\mathrm{Ni}^{2+}\right)$. Therefore, we investigated whether spontaneous bursts in ET cells are triggered by the LTS. Sodium currents were blocked by TTX $(1 \mu \mathrm{M})$ to isolate $\mathrm{Ca}^{2+}$ currents (Fig. 7A). In all four ET cells tested, intracellular injection of depolarizing current pulses in the presence of TTX generated long-duration spikes (109 $\pm 3 \mathrm{msec}$ ), LTSs (Fig. $7 A$ ). The calcium spikes were all-or-none in nature, and only one calcium spike was generated for each depolarizing pulse from a holding potential of $-60 \mathrm{mV}$; the threshold for LTS activation was $-38 \pm 0.3 \mathrm{mV}$. Cadmium $(100 \mu \mathrm{M})$ and nickel $(1 \mathrm{mM})$ were applied to block high- and low-threshold calcium channels (Fox et al., 1987); this blocked the LTS (Fig. 7A). These results confirm that ET cells generate calcium spikes that are eliminated by calcium channel blockers.

We next investigated the potential role of the LTS in spontaneous burst generation. We recorded from four ET cells in the presence of synaptic blockers in cell-attached mode to prevent bursting rundown (Fig. $7 B)$. After the addition of $\mathrm{Cd}^{2+}(100 \mu \mathrm{M})$ and $\mathrm{Ni}^{2+}(1$ $\mathrm{mM})$, spontaneous bursting persisted, although the frequency of bursting decreased (Fig. 7B). The duration of each burst was also prolonged by the calcium channel blockers from $85 \pm 15$ to $222 \pm 20$ $\operatorname{msec}(n=4 ; p<0.001)$, as shown in Figure $7 B$, in which the ET cell was recorded initially in cell-attached mode and then switched to whole-cell mode. This suggests that $\mathrm{Ca}^{2+}$-dependent mechanisms may contribute to burst termination or burst timing. Finally, in the presence of $\mathrm{Cd}^{2+}$ and $\mathrm{Ni}^{2+}$, positive current pulses failed to evoke an LTS but did evoke a burst of action potentials (Fig. 7C); the burst was eliminated by subsequent addition of TTX $(1 \mu \mathrm{M})$. Together, these results indicate that ET cells have a calcium-dependent spike, 


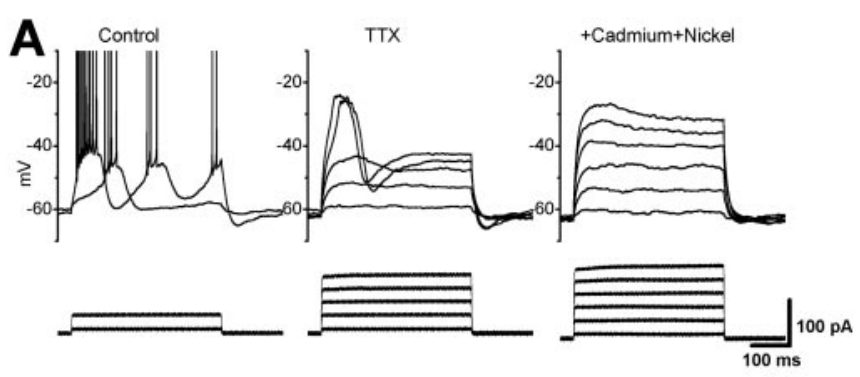

B
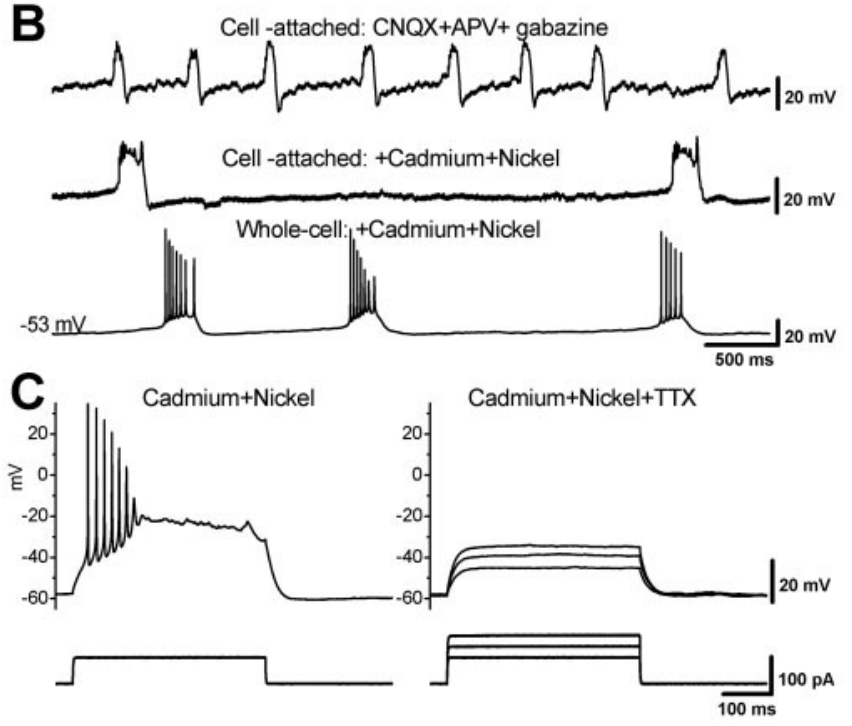

Figure 7. Calcium channels are not essential for spontaneous burst generation. $A$, When sodium channels were blocked by TTX (1 $\mu \mathrm{m})$, intracellular injection of depolarizing current pulse of sufficient amplitude generated an all-or-none calcium spike with a threshold of approximately $-40 \mathrm{mV}$, and it was blocked by the calcium channel blockers cadmium (100 $\mu \mathrm{m}$ ) and nickel ( $1 \mathrm{~mm}$ ). $B$, An ET cell was recorded before and during application of calcium channel blockers in cell-attached mode (top two traces) to prevent bursting rundown and immediately after switching to whole-cell mode (bottom trace). The calcium channel blockers cadmium (100 $\mu \mathrm{m})$ and nickel (1 $\mathrm{mm}$ ) lowered the bursting frequency but did not prevent burst generation. Burst duration was prolonged by the calcium channel blockers (compare bursts in top trace to those in middle and bottom traces). $C$, In the same cell shown in $B$, positive current pulses in the presence of cadmium and nickel evoked action potentials (left panel) that were blocked by an additional application of TTX ( $1 \mu \mathrm{m}$; right panel). No calcium spikes were observed in the presence of TTX or the calcium channel blockers. All recordings in this figure were made in the presence of synaptic blockers.

but this event is not essential for either spontaneous or depolarization-evoked bursting in ET cells.

In many types of neurons, spontaneous bursting is triggered by a persistent sodium current $\left(\mathrm{I}_{\mathrm{NaP}}\right)$ that is partially available at resting membrane potentials (Azouz et al., 1996; Brumberg et al., 2000; Su et al., 2001). Thus, we next tested for the presence of $\mathrm{I}_{\mathrm{NaP}}$ in ET cells recorded in the presence of synaptic blockers $(n=4)$. For this purpose, we used a voltage-clamp ramp protocol (Del Negro et al., 2002). Ramps were generated over the voltage interval of -80 to $-40 \mathrm{mV}$ at speeds sufficiently slow $(30 \mathrm{mV} / \mathrm{sec})$ to prevent activation of the rapidly inactivating sodium channels involved in action potential generation (Fig. 8A). The inward current revealed by this protocol was completely blocked by $1 \mu \mathrm{M}$ TTX (Fig. $8 A$ ). The average magnitude of the TTX-sensitive $\mathrm{I}_{\mathrm{NaP}}$ obtained from four ET cells by subtraction of $I-V$ curves is shown in Figure $8 B$. $\mathrm{I}_{\mathrm{NaP}}$ has a mean activation threshold of approximately $-60 \mathrm{mV}$, and it increases in amplitude with further membrane depolarization until the membrane potential reaches threshold for spike generation. Therefore, $\mathrm{I}_{\mathrm{NaP}}$ is active at the
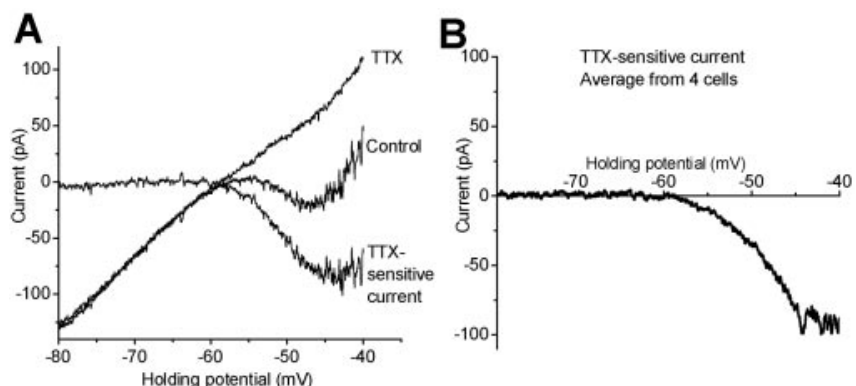

Figure 8. Evidence for a persistent sodium current in ET cells. $A$, Voltage-clamp ramps were performed from -80 to $-40 \mathrm{mV}$ at a speed of $30 \mathrm{mV} / \mathrm{sec}$ in control and during application of TTX (1 $\mu \mathrm{M})$. The sodium current generated using this protocol was calculated by subtracting the current-voltage curves in both conditions. $B$, As shown by the average from four cells, sodium current is activated at holding potentials more positive than $-60 \mathrm{mV}$. All recordings in this figure were performed from spontaneously bursting ET cells in the presence of synaptic blockers.

\section{In CNQX+APV+gabazine}

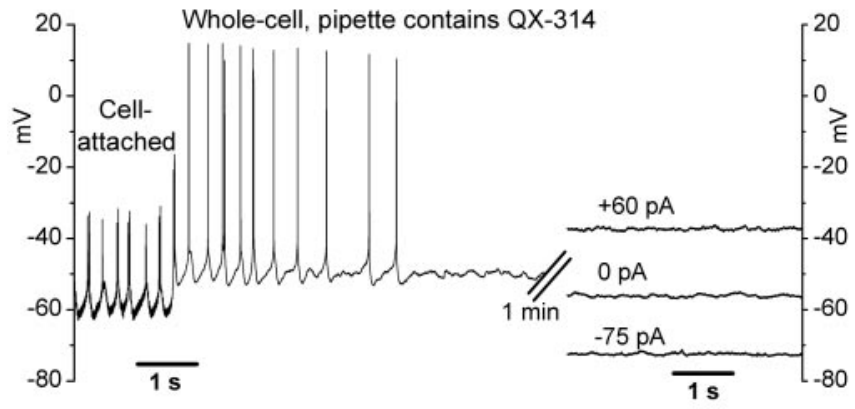

Figure 9. Sodium channels are essential for spontaneous burst generation. A bursting cell was initially recorded in cell-attached mode in the presence of synaptic blockers. Subsequent current-clamp recording in whole-cell mode with a pipette filled with QX-314 (10 mm) showed that bursting and membrane oscillations disappeared progressively after membrane rupture and intracellular dialysis with QX-314. Right traces show selected recordings 60 sec after switching to whole-cell mode (top trace break). Rhythmic membrane depolarizations and bursting could not be restored by steady intracellular injection of positive or negative current.

voltages that encompass the voltage range of slow membrane depolarizations [i.e., from the resting membrane potential $(-53$ $\mathrm{mV})$ up to the threshold for spike generation $(-46 \mathrm{mV})]$, whereas the calcium spike is only active at voltages higher than $-38 \mathrm{mV}$. Thus, $\mathrm{I}_{\mathrm{NaP}}$ is well suited to generate the rhythmic depolarizations associated with bursting.

To further investigate the role of sodium channels in spontaneous burst generation, we next blocked sodium channels of single recorded cells using patch pipettes containing the sodium channel blocker QX-314 (10 mM) (Brumberg et al., 2000). In four of the seven experiments, synaptic blockers were added to prevent spontaneous EPSPs. Initially, each cell was recorded in cellattached mode for $\sim 3-5$ min to obviate rundown and establish burst parameters (Fig. 9). Next, the recording was switched to whole-cell mode to infuse the cell with QX-314. In all seven cells tested, spike bursts as well as the underlying depolarizing envelope were completely abolished within $30-60 \mathrm{sec}$ (Fig. 9). The elimination of rhythmic bursting by QX-314 was not attributable to a change in membrane potential, because bursting could not be restored by either depolarizing or hyperpolarizing currents (Fig. 9). Consistent with the findings of McQuiston and Katz (2001), positive current pulses were still able to evoke an all-ornone LTS (duration, $143 \pm 4 \mathrm{msec}$; threshold, $-35 \pm 2 \mathrm{mV}$ ) in 
the presence of intracellular QX-314 (data not shown); the LTS was eliminated by the addition of the calcium channel blockers $\mathrm{Cd}^{2+}(100 \mu \mathrm{M})$ and $\mathrm{Ni}^{2+}(1 \mathrm{~mm})$. Thus, blockade of the sodium channels eliminates the depolarizing envelope that generates spontaneous bursting, even though the calcium spike is still present. Together, these results indicate that spontaneous bursting in ET cells requires the $\mathrm{I}_{\mathrm{NaP}}$ but not the LTS.

\section{ET cell bursts are entrained by patterned ON input}

The present results indicate that ET cells have spontaneous burst frequencies ranging from 0.5 to $9 \mathrm{~Hz}$. This bursting range overlaps substantially with the theta frequency band prominent in olfactory-limbic neural activity (Adrian, 1950; Macrides et al., 1982; Eeckman and Freeman, 1990; Kay and Laurent, 1999; Kay, 2003), including the $5-10 \mathrm{~Hz}$ rhythmic sniffing pattern rodents use when investigating novel odors (Welker, 1964; Komisaruk, 1970; Uchida and Mainen, 2003). Single ON stimuli uniformly elicited a short latency EPSC in ET cells. Thus, we wondered how ET cells would respond to repetitive ON input that simulates the patterned input they receive during rhythmical sniffing? Because each ET cell has its own resting burst frequency, a given ET cell might only be entrained by repetitive $\mathrm{ON}$ stimulation at or close to its resting burst frequency. In this case, each cell would be tuned to inputs over a limited range of sniff frequencies. Alternatively, ET cells might be able to follow repetitive ON stimulation over a broad frequency range, in which case the population of ET cells would be entrained by repetitive inputs spanning the range of rhythmical sniffing.

To investigate entrainment, we examined the responses of seven ET cells to trains of $10 \mathrm{ON}$ stimuli delivered at three frequencies within the theta range: 5, 8, and $10 \mathrm{~Hz}$ (Fig. 10). At all frequencies, there was a decrement in burst amplitude from the first to the second stimulus. This is to be expected because of the fact that $\mathrm{ON}$ terminals are subject to presynaptic inhibition following a single ON stimulus (Aroniadou-Anderjaska et al., 2000; Ennis et al., 2001). Notwithstanding this paired-pulse decrement, the ET cell bursts were readily entrained to $5 \mathrm{~Hz}$ ON stimuli. There was a small, progressive reduction in burst amplitude but after 10 stimuli, the burst amplitude was still $\sim 70 \%$ of the control response.

A reduction in integrated burst amplitude could be caused by a decrease in the number of spikes per burst, by an increase in the number of trials in which the burst was not evoked (i.e., failures), or by both. As shown in Figure 10, there was only a small incidence of burst failures at $5 \mathrm{~Hz}$ stimulation, indicating that the reduction in burst amplitude was primarily attributable to a decrease in the number of spikes per burst over the course of the 10 stimuli. ET cell bursts were also entrained to 8 and $10 \mathrm{~Hz}$ stimuli, with burst amplitudes maximally reduced to $\sim 40$ and $25 \%$ of the initial amplitude, respectively, by the end of the stimulus train. At these higher frequencies, there was an increased incidence of burst failures as well as reduction in the number of spikes per burst. There was no clear relationship between the spontaneous burst frequency of the cell and its ability to be entrained by repetitive ON input $(n=7 ; p>0.3$; linear regression fit of the relationship between the success rate of evoking a burst by the end of a stimulus train and the spontaneous burst frequency of the cell). These results indicate that repetitive sensory input is capable of entraining ET cells across a range of frequencies characteristic of rodent investigative sniffing.

\section{Discussion}

The present study demonstrates that each glomerulus contains a population of morphologically distinct, rhythmically bursting

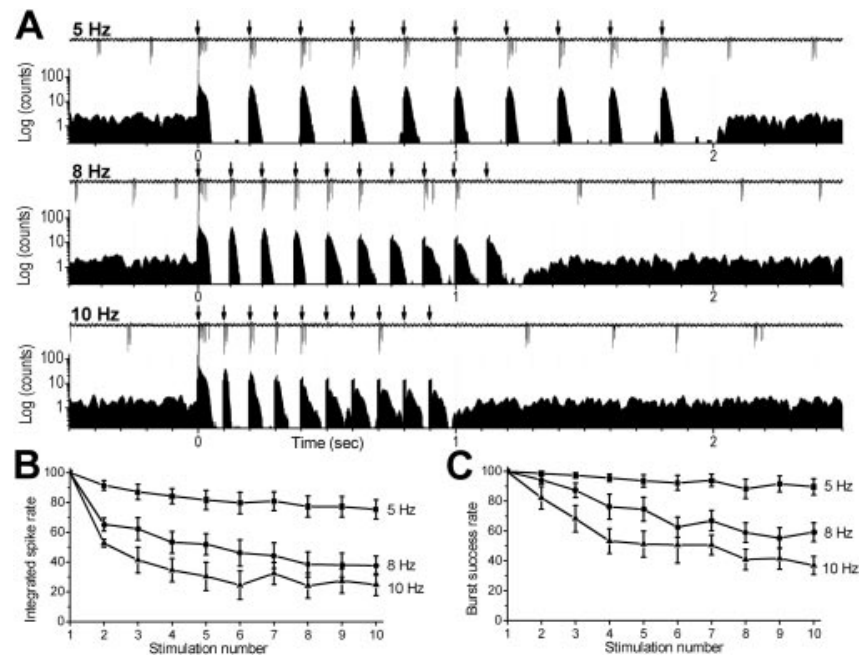

Figure 10. ET cells are entrained by patterned $O N$ input at theta frequencies. A, Peristimulus time histograms (PSTH) showing the activity of an ET cell in response to a train of $100 \mathrm{~N}$ stimuli (arrows) delivered at $5 \mathrm{~Hz}$ (top PSTH), $8 \mathrm{~Hz}$ (middle PSTH), and $10 \mathrm{~Hz}$ (bottom PSTH). A sample trace of extracellular unit recording is shown above each PSTH. Note that the ET cell spike bursts were synchronized to the $0 \mathrm{~N}$ stimuli at all frequencies. At higher frequencies ( 8 and $10 \mathrm{~Hz}$ ), bursts occasionally failed to be evoked toward the end of the train. Each PSTH contains activity accumulated over 150 consecutive trains delivered at intervals of $10 \mathrm{sec}$ (bin width, $1 \mathrm{msec}$ ). $B$, Grouped data from seven ET cells (mean spontaneous frequency, $3.6 \pm 0.7$ bursts/sec; range, $1.6-6.4$ bursts $/ \mathrm{sec}$ ). The amplitude of the $0 \mathrm{~N}$-evoked response was measured by integrating the PSTH for $50 \mathrm{msec}$ after each of the $100 \mathrm{~N}$ stimuli. The response to each stimulus is expressed as a percentage of the response to the first stimulus in the train. A gradual decrement occurred in response to the 10 stimuli, which increased with the frequency of the train. C, Grouped data from the same seven cells analyzed in $B$ showing the success rate of $0 \mathrm{~N}$ stimuli in evoking a burst for each stimulus in the train. Note that although $\mathrm{ET}$ cells responded faithfully to $0 \mathrm{~N}$ stimulation with an all-or-none burst, the probability of failure to evoke bursts increased with increasing stimulus frequency. The observation that the success rate is higher than the integrated spike rate at all frequencies (compare the lower 2 graphs) indicates that the strength of the evoked bursts (i.e., the number of spikes per burst) was reduced after repetitive stimulation.

neurons: the ET cells. Spontaneous rhythmic bursting in ET cells is generated by $\mathrm{I}_{\mathrm{NaP}}$, which is active at resting membrane potential. Rhythmic bursting occurs at frequencies overlapping the theta frequency band characteristic of sniffing in rodents. ET cells receive ON input, and ET cell spike bursts readily entrain to patterned $\mathrm{ON}$ input delivered at theta frequencies. An important physiological function of the glomerular ET cell network may be to synchronize glomerular activity during sniffing.

\section{Morphology of ET cells}

The morphology of ET cells observed in the present study is consistent with classical neuroanatomical studies (Pinching and Powell, 1971a,b; Macrides and Schneider, 1982). The cell bodies are situated in the deep half of the glomerular layer, and the vast majority have a single apical dendrite that ramifies extensively throughout most $(\sim 80 \%)$ of its target glomerulus, similar to the pattern for mitral cell apical dendrites. Dendritic spines were sparsely present in $29 \%$ of ET cells, in agreement with recent observations by McQuiston and Katz (2001) that some ET cells have spines. Consistent with previous studies (Macrides and Schneider, 1982), only $37 \%$ of the ET cells exhibited secondary dendrites. Because the slice preparation cuts the dendrites of some cells, our data may underestimate the numbers of ET cells that extend secondary dendrites into the EPL. Despite this potential limitation, however, $63 \%$ of the filled ET had visible axons, which coursed toward or entered the EPL. The synaptic targets of these extraglomerular axons are unknown but are important to 
determine, because ET cells may provide a burst input to extraglomerular targets in the bulb and possibly beyond.

\section{ET cells burst rhythmically}

The most distinctive physiological feature of ET cells is their spontaneous rhythmical bursting. Glomerular layer cells with burst characteristics have been reported in vivo (Getchell and Shepherd, 1975; Wellis and Scott, 1990). However, because of the difficulty of recording small JG neurons in vivo, the identity of these cells and the basis of their bursting behavior remained unknown. The rhythmical burst-firing mode was characteristic of morphologically confirmed ET neurons. In contrast, PG and SA cells do not spontaneously generate spike bursts nor can they be induced to do so by intracellular current injections. Each ET cell bursts at its own characteristic frequency. As a population, ET cell burst frequencies range from $\sim 1$ to $8 \mathrm{~Hz}$, with a mean of $3.3 \pm$ 0.18 bursts/sec. This range overlaps with the theta frequency range prominent in oscillatory neural activity in the rodent olfactory network. The theta range includes components related to low frequency $(1-3 \mathrm{~Hz})$ "passive" sniffing as well as a higher frequency component $(5-10 \mathrm{~Hz})$ characteristic of active investigative sniffing (Adrian, 1950; Welker, 1964; Macrides et al., 1982; Eeckman and Freeman, 1990; Kay and Laurent, 1999; Kay, 2003; Uchida and Mainen, 2003).

Several lines of evidence indicate that bursting is an intrinsic property of ET cells. First, bursting deteriorates rapidly after establishment of whole-cell recording mode. This pronounced rundown of bursting may explain the low reported incidence of spontaneous bursting in JG cells in previous whole-cell recording studies (Bardoni et al., 1995; Puopolo and Belluzzi, 1996, 1998; McQuiston and Katz, 2001). The rundown of bursting could be attributable to intracellular dialysis of an intracellular messenger important to maintain spontaneous activity (Alreja and Aghajanian, 1995). Additional evidence in support of the intrinsic mechanism for bursting is the findings that: (1) burst frequency is voltage dependent and (2) bursting persists in blockers of ionotropic and metabotropic glutamate receptors and $\mathrm{GABA}_{\mathrm{A}}$ receptors. This eliminates the possibility that bursting is driven by glutamatergic input from the ON, glutamatergic dendrodendritic interactions among ET cells or mitral cells, or by disinhibition (Aroniadou-Anderjaska et al., 1999; Isaacson, 1999; Carlson et al., 2000; Freidman and Strowbridge, 2000; Schoppa and Westbrook, 2001; Salin et al., 2001). Moreover, spontaneous bursting was not blocked by $\mathrm{Cd}^{2+}$, which suppresses $\mathrm{Ca}^{2+}$-dependent neurotransmitter release, ruling out the potential involvement of other neurotransmitters.

\section{Mechanism of spontaneous burst generation}

In agreement with McQuiston and Katz (2001), we found that depolarizing current injections evoke low-threshold $\mathrm{Ca}^{2+}$ spikes in ET cells. This suggested that the LTS may generate ET cell bursting. However, this is unlikely for several reasons. First, the present results show that the LTS is eliminated by the calcium channel blockers $\mathrm{Cd}^{2+}(100 \mu \mathrm{M})$ and $\mathrm{Ni}^{2+}(1 \mathrm{mM})$, confirming the finding of McQuiston and Katz (2001). However, bursting persisted in the same cells after the LTS was blocked. Second, ET cell bursting was abolished by extracellular TTX or by intracellular QX-314, whereas the LTS persisted. Third, the activation threshold of the LTS $(-38 \mathrm{mV})$ was $\sim 15 \mathrm{mV}$ more depolarized than the membrane potentials from which bursting arises, on average $-53 \mathrm{mV}$. Calcium may modulate bursting, because calcium channel blockers prolonged burst duration. Calcium channel blockers also increased the interburst interval, but this could be because of a charge screening effect resulting from the concentration of $\mathrm{Ni}^{2+}$ used (1 mM), which shifts activation of $\mathrm{I}_{\mathrm{NaP}}$ to more positive potentials (Su et al., 2001). ET cells have a hyperpolarization-activated cation conductance (Ih) that is prominent at resting membrane potentials (our unpublished observations). Ih participates in burst timing and rhythmicity (DiFrancesco, 1993; Lüthi and McCormick, 1998; Pape, 1996) and is modulated by calcium. Thus, Ih and calcium may play a role in burst termination and setting the interburst interval, but this requires additional study.

Rhythmic bursting, but not the LTS, was blocked by extracellular TTX and by intracellular dialysis with QX-314. These results suggest that, as for many neocortical neurons (Brumberg et al., 2000), burst generation in ET cells requires slowly inactivating sodium channels (i.e., $\mathrm{I}_{\mathrm{NaP}}$ ). Indeed, all ET cells tested had a prominent TTX-sensitive, persistent inward current. The characteristics of this current are well suited to trigger spontaneous bursting in ET cells. The inward current activates at approximately $-60 \mathrm{mV}$, slightly hyperpolarized to the mean ET cell resting potential $(-53 \mathrm{mV})$. It is reasonable to conjecture that as this $\mathrm{I}_{\mathrm{NaP}}$ slowly depolarizes the ET cell membrane, additional sodium channels are activated, further depolarizing the membrane to the threshold for action potential generation $(-46 \mathrm{mV})$. The current maintains a level of depolarization sufficient to generate additional action potentials until another mechanism(s), possibly involving calcium (see above), terminates the burst by transiently hyperpolarizing the membrane below the activation threshold for $\mathrm{I}_{\mathrm{NaP}}$. As the membrane repolarizes, $\mathrm{I}_{\mathrm{NaP}}$ is re-engaged, and the burst cycle is repeated.

\section{Functional implications of bursting}

All ET cells generated a short latency EPSC and burst of spikes in response to single ON stimuli. The present results show that ET cells, regardless of their intrinsic spontaneous bursting frequencies, can be entrained by repetitive $5-10 \mathrm{~Hz}$ ON input. Thus, sensory input can override the intrinsic burst frequency of ET cells. However, it is interesting to note that bursting was found to be relatively stronger (more spikes per burst) at hyperpolarized membrane potentials and less regular in cells with low bursting frequencies. The increase in burst strength at hyperpolarized potentials could be because of the involvement of Ih current or de-inactivation of low-thresholdactivated $\mathrm{Ca}^{+2}$ currents in addition to the activation of $\mathrm{I}_{\mathrm{NaP}}$. The irregularity in bursting in cells with low burst frequencies could be attributable to the spontaneous EPSPs, which might play a more prominent role in regulating the interburst time intervals in slower cells. Therefore, EPSPs evoked by ON terminals will serve to reset the bursting in ET cells, which subsequently become entrained by the rhythm imposed by the pattern of sensory input.

What might be the functional consequence of such entrainment? Because of their bursting properties, ET cells may amplify sensory input onto the glomerular network in the sense that a single $\mathrm{ON}$ volley is transformed into a burst of spikes. Such amplification, combined with entrainment of the ensemble of ET cells of the same glomerulus may function to synchronize the glomerular network, including mitral cells, to sensory input, which is itself tuned to the sniffing of the animal.

Further understanding of the functional significance of ET cell bursting and sensory entrainment will require the identification of neurons that are synaptically targeted by ET cells. The literature offers little guidance on this matter. Electron microscopic studies indicate that dendrites from either mitral or tufted cells, or both, are presynaptic to the dendrites of PG and SA cells within the glomerular neuropil (Pinching and Powell, 1971a). However, because the dendrites of mitral and tufted cells cannot be distin- 
guished at the electron microscopic level, it is not possible to infer the identity of intraglomerular synaptic targets specifically of ET cells. The majority of ET cells send an axon out of the glomerular layer into deeper layers and possibly beyond. The identification of these extraglomerular targets of ET cells is also an important matter for investigation.

In conclusion, the present findings suggest that the ET cells, which are located at the first site of synaptic processing in the olfactory system, comprise a significant population of neurons that spontaneously generate rhythmic spike bursts at frequencies associated with rodent sniffing. Through synaptic interactions with other JG cells, ET cells may form an intrinsic oscillatory network that is tuned to natural rhythmic, sensory input. Simultaneous entrainment of spike bursts among ET cells associated with the same glomerulus could function to synchronize glomerular activity and preserve or perhaps enhance the fidelity of the specific odorant profile projected onto each glomerulus by receptor neurons.

\section{References}

Adrian ED (1950) The electrical activity of the olfactory bulb. Electroencephalogr Clin Neurophysiol 2:377-388.

Alreja M, Aghajanian GK (1995) Use of the whole-cell patch-clamp method in studies on the role of cAMP in regulating the spontaneous firing of locus coeruleus neurons. J Neurosci Methods 59:67-75.

Aroniadou-Anderjaska V, Ennis M, Shipley MT (1999) Dendrodendritic recurrent excitation in mitral cells of the rat olfactory bulb. J Neurophysiol 82:489-494.

Aroniadou-Anderjaska V, Zhou FM, Priest CA, Ennis M, Shipley MT (2000) Tonic and synaptically evoked presynaptic inhibition of sensory input to the rat olfactory bulb via GABA(B) heteroreceptors. J Neurophysiol 84:1194-1203.

Azouz R, Jensen MS, Yaari Y (1996) Ionic basis of spike after-depolarization and burst generation in adult rat hippocampal CA1 pyramidal cells. J Physiol (Lond) 492:211-223.

Bardoni R, Magherini PC, Belluzzi O (1995) Sodium current in periglomerular cells of frog olfactory bulb in vitro. Brain Res 703:19-25.

Belluscio L, Katz LC (2001) Symmetry, stereotypy, and topography of odorant representations in mouse olfactory bulbs. J Neurosci 21:2113-2122.

Brumberg JC, Nowak LG, McCormick DA (2000) Ionic mechanisms underlying repetitive high-frequency burst firing in supragranular cortical neurons. J Neurosci 20:4829-4843.

Carlson GC, Shipley MT, Keller A (2000) Long-lasting depolarizations in mitral cells of the rat olfactory bulb. J Neurosci 20:2011-2021.

Christodoulou C, Bugmann G (2001) Coefficient of variation (CV) vs mean interspike interval (ISI) curves: what do they tell us about the brain? Neurocomputing 38-40:1141-1149.

Cinelli AR, Hamilton KA, Kauer JS (1995) Salamander olfactory bulb neuronal activity observed by video rate, voltage-sensitive dye imaging. III. Spatial and temporal properties of responses evoked by odorant stimulation. J Neurophysiol 73:2053-2071.

Del Negro CA, Koshiya N, Butera Jr RJ, Smith JC (2002) Persistent sodium current, membrane properties and bursting behavior of pre-botzinger complex inspiratory neurons in vitro. J Neurophysiol 88:2242-2250.

DiFrancesco D (1993) Pacemaker mechanisms in cardiac tissue. Annu Rev Physiol 55:455-472.

Eeckman FH, Freeman WJ (1990) Correlations between unit firing and EEG in the rat olfactory system. Brain Res 528:238-244.

Ennis M, Zhou FM, Ciombor KJ, Aroniadou-Anderjaska V, Hayar A, Borrelli E, Zimmer LA, Margolis F, Shipley MT (2001) Dopamine D2 receptormediated presynaptic inhibition of olfactory nerve terminals. J Neurophysiol 86:2986-2997.

Fox AP, Nowycky MC, Tsien RW (1987) Kinetic and pharmacological properties distinguishing three types of calcium currents in chick sensory neurones. J Physiol (Lond) 394:149-172.

Friedman D, Strowbridge BW (2000) Functional role of NMDA autoreceptors in olfactory mitral cells. J Neurophysiol 84:39-50.

Getchell TV, Shepherd GM (1975) Synaptic actions on mitral and tufted cells elicited by olfactory nerve volleys in the rabbit. J Physiol (Lond) 251:497-522.

Hayar A, Karnup S, Shipley MT, Ennis M (2001) Synchronous activity among juxtaglomerular neurons of the rat main olfactory bulb in vitro. Soc Neurosci Abst 27:459.4.
Isaacson JS (1999) Glutamate spillover mediates excitatory transmission in the rat olfactory bulb. Neuron 23:377-384.

Johnson BA, Leon M (2000a) Modular representations of odorants in the glomerular layer of the rat olfactory bulb and the effects of stimulus concentration. J Comp Neurol 422:496-509.

Johnson BA, Leon M (2000b) Odorant molecular length: one aspect of the olfactory code. J Comp Neurol 426:330-338.

Jourdan F, Duveau A, Astic L, Holley A (1980) Spatial distribution of [14C]2-deoxyglucose uptake in the olfactory bulbs of rats stimulated with two different odours. Brain Res 188:139-154.

Karnup S, Stelzer A (1999) Temporal overlap of excitatory and inhibitory afferent input in guinea-pig CA1 pyramidal cells. J Physiol (Lond) 516:485-504.

Kauer JS (1998) Olfactory processing: a time and place for everything. Curr Biol 8:R282-R283.

Kay LM (2003) A challenge to chaotic intinerancy from brain dynamics. Chaos 13:1057-1066.

Kay LM, Laurent G (1999) Odor- and context-dependent modulation of mitral cell activity in behaving rats. Nat Neurosci 2:1003-1009.

Kinzie JM, Shinohara MM, van den Pol AN, Westbrook GL, Segerson TP (1997) Immunolocalization of metabotropic glutamate receptor 7 in the rat olfactory bulb. J Comp Neurol 385:372-384.

Komisaruk BR (1970) Synchrony between limbic system theta activity and rhythmical behavior in rats. J Comp Physiol Psychol 70:482-492.

Laurent G (2002) Olfactory network dynamics and the coding of multidimensional signals. Nat Rev Neurosci 3:884-895.

Lüthi A, McCormick DA (1998) H-current: properties of a neuronal and network pacemaker. Neuron 21:9-12.

Macrides F, Schneider SP (1982) Laminar organization of mitral and tufted cells in the main olfactory bulb of the adult hamster. J Comp Neurol 208:419-430.

Macrides F, Eichenbaum HB, Forbes WB (1982) Temporal relarionship between sniffing and the limbic $\Theta$ rhythm during odor discrimination and reversal learning. J Neurosci 2:1705-1717.

McQuiston AR, Katz LC (2001) Electrophysiology of interneurons in the glomerular layer of the rat olfactory bulb. J Neurophysiol 86:1899-1907.

Ohishi H, Akazawa C, Shigemoto R, Nakanishi S, Mizuno N (1995) Distributions of the mRNAs for L-2-amino-4-phosphonobutyrate-sensitive metabotropic glutamate receptors, mGluR4 and mGluR7, in the rat brain. J Comp Neurol 360:555-570.

Pape HC (1996) Queer current and pacemaker: the hyperpolarizationactivated cation current in neurons. Annu Rev Physiol 58:299-327.

Perkel DH, Gerstein GL, Moore GP (1967) Neuronal spike trains and stochastic point processes. I. The single spike train. Biophys J 7:391-418.

Pinching AJ, Powell TP (1971a) The neuron types of the glomerular layer of the olfactory bulb. J Cell Sci 9:305-345.

Pinching AJ, Powell TP (1971b) The neuropil of the glomeruli of the olfactory bulb. J Cell Sci 9:347-377.

Puopolo M, Belluzzi O (1996) Sodium current in periglomerular cells of rat olfactory bulb in vitro. NeuroReport 7:1846-1850.

Puopolo M, Belluzzi O (1998) Inhibitory synapses among interneurons in the glomerular layer of rat and frog olfactory bulbs. J Neurophysiol 80:344-349.

Sahara Y, Kubota T, Ichikawa M (2001) Cellular localization of metabotropic glutamate receptors mGluR1, 2/3, 5 and 7 in the main and accessory olfactory bulb of the rat. Neurosci Lett 312:59-62.

Salin PA, Lledo PM, Vincent JD, Charpak S (2001) Dendritic glutamate autoreceptors modulate signal processing in rat mitral cells. J Neurophysiol 85:1275-1282.

Schoppa NE, Westbrook GL (2001) Glomerulus-specific synchronization of mitral cells in the olfactory bulb. Neuron 31:639-651.

Shipley MT, Mclean JH, Zimmer LA, Ennis M (1996) The olfactory system. In: Handbook of chemical neuroanatomy, Vol 12, Integrated systems of the CNS, Pt III (Björklund A, Hökfelt T, Swanson LW, eds), pp 469-573. Amsterdam: Elsevier.

Su H, Alroy G, Kirson ED, Yaari Y (2001) Extracellular calcium modulates persistent sodium current-dependent burst-firing in hippocampal pyramidal neurons. J Neurosci 21:4173-4182.

Uchida N, Mainen ZF (2003) Speed and accuracy of olfactory discrimination in the rat. Nat Neurosci 6:1224-1229.

Wehr M, Laurent G (1996) Odour encoding by temporal sequences of firing in oscillating neural assemblies. Nature 384:162-166.

Welker WI (1964) Analysis of sniffing of the albino rat. Behaviour 22:223-244.

Wellis DP, Scott JW (1990) Intracellular responses of identified rat olfactory bulb interneurons to electrical and odor stimulation. J Neurophysiol 64:932-947. 